\title{
SALINIDADE EM PETRÓLEO BRUTO: OTIMIZAÇÃO DE METODOLOGIA E PROPOSTA DE UM NOVO MÉTODO PARA EXTRAÇÃO DE SAIS EM PETRÓLEO
}

\author{
Milton K. Morigaki*, Roberta Q. F. Chimin, Cristina M. dos S. Sad, Paulo R. Filgueiras e Eustaquio V. R. de Castro \\ Departamento de Química, Universidade Federal do Espírito Santo, Av. Fernando Ferrari, s/n, 29060-900 Vitória - ES, Brasil \\ Júlio C. M. Dias
}

CENPES/PETROBRAS, Cidade Universitária Q.7, 21949-900 Rio de Janeiro - RJ, Brasil

Recebido em 17/4/09; aceito em 20/9/09; publicado na web em 23/2/10

\begin{abstract}
SALINITY OF CRUDE OIL: OPTIMIZATION OF METHODOLOGY AND NEW METHOD FOR EXTRACTION OF SALT IN PETROLEUM. The quantity of salts in the crude oils depends on the origin and of the wells production and these salts cause several problems during the transport and the process of refine as corrosions, incrustations and deactivation of the employed catalysts in the refineries. In this study were implemented changes for improvements in the execution of ASTM D 6470 method and has also developed a new methodology of extraction system of salts using process of mechanical agitation without heating. The results of the optimization produce larger efficiency and safety to the process compared to the traditional ASTM method.
\end{abstract}

Keywords: salinity; petroleum; potentiometric tritation.

\section{INTRODUÇÃO}

O petróleo é constituído por uma mistura de compostos químicos orgânicos (hidrocarbonetos), cujo estado físico considerando condições normais de temperatura e pressão é predominantemente líquido, podendo assumir o estado gasoso quando a mistura contém uma maior porcentagem de componentes com baixo peso molecular. O petróleo geralmente se apresenta associado à água que, por sua vez, contém sais minerais em solução. Essa associação é devida, sobretudo, à tendência natural de acúmulo da água salgada gerada pelas formações geológicas para as partes inferiores de reservatórios de petróleo. Com métodos adequados e racionais de produção, é possível obtê-lo com teor mínimo de água salgada. Todavia, à medida que o campo vai sendo explorado, há a tendência de aumentar a proporção de água no óleo extraído. ${ }^{1,2}$

Diante da complexidade de sua composição, não existem dois petróleos idênticos. As diferenças na composição, além de influírem nas suas propriedades, têm igualmente influência ponderável sobre a técnica de refino e, frequentemente, determinam os produtos que podem ser obtidos. Desta maneira, é óbvio que nem todos os derivados podem ser obtidos direta e economicamente de qualquer tipo de petróleo, da mesma forma que não existe um esquema universal de refino adaptável a qualquer tipo de óleo bruto. ${ }^{2}$

Nos campos de produção, após a separação dos gases e da água livre que é removida por decantação, o óleo sofre desidratação no equipamento conhecido como tratador de óleo. A dessalgação normalmente é feita em uma refinaria de petróleo. A água salgada apresenta-se predominantemente sob a forma de gotas dispersas no petróleo, constituindo emulsões do tipo água em óleo. Uma emulsão é um sistema heterogêneo líquido que consiste de dois líquidos não miscíveis, um dos quais intimamente disperso na forma de gota; a emulsificação tanto pode ocorrer durante a própria formação do óleo como nos equipamentos mecânicos, tais como bombas, tubulações e separadores.

Apesar do tratamento que o óleo sofre nos campos de produção reduzir consideravelmente os teores de água, sais e sedimentos, os requisitos de altas vazões de óleo produzido impedem a remoção total da água salgada do petróleo. Por esta razão, o óleo minimamente processado é transportado através de oleodutos e navios até as refinarias,

\footnotetext{
*e-mail: morigaki@npd.ufes.br
}

onde é novamente dessalgado e desidratado, de modo a atingir teores de água e sais suficientemente baixos para as operações de refino.

A porcentagem de sal existente no petróleo deve ser mantida abaixo de certos limites. $\mathrm{O}$ teor salino máximo aceito na produção é de $570 \mathrm{mg} / \mathrm{L}$ e pelas refinarias é de $285 \mathrm{mg} / \mathrm{L}$, sendo geralmente expresso como a massa de cloreto de sódio, em mg, dissolvida em $1 \mathrm{~L}$ de petróleo, ao passo que o teor de água e sedimentos máximo possível é de 1\% BSW (Basic Sediments and Water - teor de água e sedimentos). ${ }^{3}$ Assim, para atingir as especificações da refinaria, o petróleo é submetido ao processo de desidratação/dessalgação antes de ser transportado dos campos produtores. Por fim, o petróleo recebido pelas refinarias é novamente dessalgado com a finalidade de reduzir o teor de sais para níveis inferiores a $5 \mathrm{mg} / \mathrm{L}$.

Nas refinarias, o petróleo com excesso de sal afeta a carga das unidades, ocasionando a sua redução, diminuindo o tempo de campanha (período compreendido entre a partida e a parada de uma unidade para limpeza, inspeção e reparos), aumentando excessivamente o tempo de parada e acarretando substituição mais frequente de equipamentos, devido à corrosão provocada pelo sal. Além disso, produzir óleos com boa qualidade com baixa quantidade de sal também ajuda a minimizar a energia requerida para o seu bombeamento e transporte. ${ }^{4}$

Os sais contidos no petróleo constituem uma fonte de corrosão por gerarem ácido clorídrico nas condições reinantes nos equipamentos de destilação. A ação corrosiva torna-se ainda mais acentuada pela presença de compostos sulfurosos $\left(\mathrm{H}_{2} \mathrm{~S}\right.$, mercaptanas etc.) e ocorrência de uma reação de oxidação-redução entre estes compostos e o ácido clorídrico, derivado dos sais por hidrólise. $\mathrm{O}$ ácido ataca o ferro, formando cloreto de ferro, o qual, por sua vez, reage com o gás sulfídrico, para produzir sulfeto de ferro e ácido clorídrico. ${ }^{3}$ Apesar das águas de formação serem compostas de vários tipos de sais, costuma-se relacionar a salinidade global dessas águas em base de cloreto de sódio. Os cloretos são elementos muito ativos no processo de corrosão. O seu efeito corrosivo está associado a sua hidrólise, quando em solução aquosa e submetido a elevadas temperaturas, formando compostos ácidos que, quando condensados, promovem rápida corrosão nas torres de refino. ${ }^{5}$

A crescente busca por qualidade, produtividade e eficiência dos processos de desidratação/dessalgação tem exigido o uso de técnicas e estratégias para o monitoramento e a otimização desses processos. Ainda agora, com a descoberta e exploração de petróleo na camada 
pré-sal que exige um custo alto de produção, o processo aqui descrito vem ao encontro da necessidade de diminuição dos custos operacionais do óleo produzido nesta nova modalidade. Porém, diante da falta de instrumentos adequados ao monitoramento do teor de sais em correntes oleosas, praticamente inexistem relatos na literatura sobre o monitoramento da dessalgação de petróleos. Alguns esforços que buscam correlacionar variável de processo com desempenho da dessalgadora têm sido relatados na literatura ${ }^{6} \mathrm{e}$ a eficiência na remoção de sais tem sido avaliada através de análises feitas em laboratório.

Vários métodos são comumente utilizados para monitorar e determinar a salinidade em petróleo (método de Möhr, titulação de precipitação com nitrato de prata ASTM D $512^{7}$ ), método de extração e titulação potenciométrica ASTM D $6470^{8}$ e o método é fundamentado na técnica de condutivimetria, segundo a Norma ASTM D $3230^{\circ}$ (recentemente implantado na indústria de petróleo).

No caso particular da caracterização do teor de sais, as normas técnicas disponíveis fornecem resultados com alta incerteza, fruto das dificuldades da avaliação da salinidade em petróleos. Isto ocorre pelo fato de tais técnicas serem geralmente fundamentadas em procedimentos de extração por solvente ou por medida de propriedades elétricas.

A extração de sais por solvente (norma ASTM D $6470^{8}$ ) depende fortemente do grau de contato ou mistura do solvente com a amostra. Para óleos muito viscosos, a eficiência da mistura é prejudicada e os procedimentos de extração tendem a fornecer resultados com baixas eficiências. Assim, o uso de normas padronizadas para determinação de salinidade, na maioria das vezes, não serve de garantia de sucesso para a análise, já que tais normas não são universais para qualquer tipo de petróleo. O sucesso do uso destes métodos padronizados depende certamente de adaptações para cada tipo de petróleo, que surgem com a experiência prática de analistas. Estes métodos têm sido alvos de discussões e atualizações periódicas, de modo a atender convenientemente um bom número de situações.

A busca por elevadas eficiências nos processos de dessalgação e desidratação nas plantas de produção e refino de petróleos é um desafio da indústria petrolífera. O fechamento do balanço de massa de sais não vem sendo satisfatório há bastante tempo. As técnicas atuais de caracterização utilizadas na determinação da concentração de sais apresentam deficiências, devido à complexidade dos variados tipos de petróleos brasileiros. Diante do exposto, é necessário o investimento em pesquisas visando otimização ou investimento de novas técnicas para a determinação do teor de sais em petróleo.

\section{PARTE EXPERIMENTAL}

As análises de monitoramento da salinidade em petróleo foram efetuadas no Laboratório de Pesquisa e Desenvolvimento de Metodologias para Análises de Petróleo (Labpetro) do Departamento de Química (DQUI) da Universidade Federal do Espírito Santo (UFES).

Para realização da otimização do sistema de extração de sais a quente (com frascos de $500 \mathrm{~mL}$ e $2 \mathrm{~L}$ ) foi utilizada uma amostra interlaboratorial de referência internacional de óleo leve ( ${ }^{\circ}$ API de 30,7) fornecida pela ASTM e uma amostra de referência secundária interna de óleo pesado ( ${ }^{\circ} \mathrm{API}$ de 16,8 ) com propriedades físico-químicas conhecidas e selecionada de um campo petrolífero monitorado constantemente para controle de qualidade do laboratório.

Para desenvolvimento do sistema de extração de sais com agitação mecânica, sem aquecimento, foram utilizadas 8 amostras de óleos leves ( ${ }^{\circ}$ API de 32,0) no período de março de 2007 a abril de 2008 , provenientes de um mesmo campo petrolífero localizado no estado do Espírito Santo (Brasil).

As análises de teor salino foram realizadas nos tituladores automáticos modelos Titrando 808 e 809, marca Metrohm, com bureta de $20 \mathrm{~mL}$ e eletrodo combinado de prata para meio aquoso.

\section{Análise do teor de sal utilizando extração a quente}

Nos tópicos a seguir, serão abordados os procedimentos experimentais para determinação do índice de salinidade total (IST) utilizando frascos extratores a quente, empregando a norma ASTM D-6470 ${ }^{8}$ com alterações.

\section{Preparo da amostra de petróleo para extração nos frascos extratores}

Para o preparo da amostra de óleo leve ( ${ }^{\circ} \mathrm{API}$ de 30,7), homogeneizou-se e pesou-se uma massa de aproximadamente 40,0 $\pm 0,1 \mathrm{~g}$ em um béquer de $250 \mathrm{~mL}$. Acrescentou-se $70 \pm 1 \mathrm{~mL}$ de xileno vertendo-se lentamente sobre a amostra, sob agitação manual por aproximadamente 3 min e transferiu-se para o frasco extrator de $500 \mathrm{~mL}$ ou $2 \mathrm{~L}$. (Figura 1) e, na sequência, adicionou-se ao béquer $25 \pm 1 \mathrm{~mL}$ de isopropanol e 15 $\pm 1 \mathrm{~mL}$ de acetona. Aqueceu-se a mistura no frasco extrator até o início da ebulição e ajustou-se o termostato, previamente calibrado para uma ebulição constante e vigorosa, mantida por $2 \mathrm{~min}$, sem causar projeções ou inundação do condensador. Interrompeu-se o aquecimento e após o término da ebulição acrescentou-se $125 \pm 1 \mathrm{~mL}$ de água deionizada pré-aquecida em torno de $80{ }^{\circ} \mathrm{C}$. Retomou-se a ebulição do frasco extrator por mais $15 \mathrm{~min}$. Após o resfriamento da solução e separação das duas fases, drenou-se a fase inferior (fase aquosa), utilizando-se um papel de filtro para reter algum óleo.

O preparo da amostra de óleo pesado $\left({ }^{\circ} \mathrm{API}\right.$ de 16,8$)$ segue o mesmo procedimento descrito anteriormente, entretanto, por ser pouco fluida à temperatura ambiente, a amostra foi homogeneizada por $5 \mathrm{~min}$ no agitador mecânico Ultra Turrax T-25 com haste dispersiva $25 \mathrm{G}$ a $11000 \mathrm{rpm}$ e, após adição de $70 \pm 1 \mathrm{~mL}$ de xileno, a mesma foi pré aquecida a $60{ }^{\circ} \mathrm{C}$ para facilitar transferência para o frasco extrator.

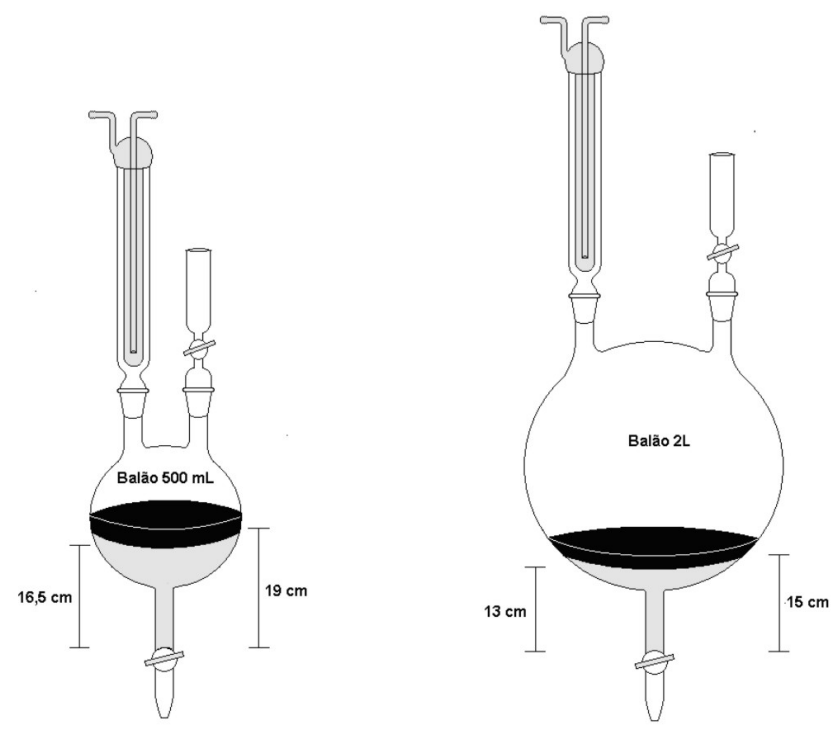

Figura 1. Frascos de capacidade $500 \mathrm{~mL}$ e 2 L para extração de sais em petróleo

\section{Verificação da influência do tempo de extração de sais dos frascos extratores}

Para a verificação de possíveis modificações no tempo de extração de sais dos frascos extratores foi realizado o mesmo procedimento descrito acima, alterando-se apenas os tempos de ebulição de 2 e 15 min (denominados neste trabalho de "Tempo ASTM") para 5 e 30 min (denominados neste trabalho de "Tempo otimizado"), respectivamente. 
Observação: Segundo a norma de referência ASTM ${ }^{8}$ o isopropanol pode ser substituído pelo etanol na extração da amostra. Devido a alguma solubilização do isopropanol e da acetona na fase óleo, o volume do extrato aquoso drenado deve ser próximo de $160 \mathrm{~mL}$.

\section{Determinação do índice de sal na fase aquosa por potenciometria}

Para a determinação do IST na fase aquosa extraída da amostra de óleo utilizou-se uma alíquota de $25,00 \mathrm{~mL}$ para amostras com altos teores e de $50,00 \mathrm{~mL}$ para amostras com baixos teores do extrato aquoso. Transferiu-se para um béquer de $250 \mathrm{~mL}$ e adicionou-se 10,00 $\mathrm{mL}$ da solução padrão de cloreto de sódio $1,00 \mathrm{mmol} / \mathrm{L}$. Ajustouse o volume da solução para $150 \mathrm{~mL}$ com acetona e adicionou-se aproximadamente $0,5 \mathrm{~g}$ de nitrato de bário, com posterior agitação. Iniciou-se a titulação potenciométrica da alíquota amostral com solução padrão de nitrato de prata $0,0100 \mathrm{~mol} / \mathrm{L}$.

\section{Extração e análise do teor de sal utilizando extração sem aquecimento constante}

Nos tópicos a seguir, serão apresentados os procedimentos experimentais para extração de sais em frasco erlenmeyer e determinação de sais utilizando amostras de óleo sem aquecimento constante.

\section{Preparo e extração de sais da amostra de petróleo utilizando frascos erlenmeyer}

Após homogeneização da amostra, pesou-se uma massa de aproximadamente $40,0 \pm 0,1 \mathrm{~g}$ de petróleo leve ( ${ }^{\circ} \mathrm{API}$ de 32,0) em um béquer de $250 \mathrm{~mL}$. Acrescentou-se $70 \pm 1 \mathrm{~mL}$ de xileno vertendo-se lentamente sobre a amostra, sob agitação manual, de aproximadamente $3 \mathrm{~min}$, até completa dissolução da mesma. Transferiu-se, quantitativamente, a solução para um erlenmeyer de $500 \mathrm{~mL}$ com rolha esmerilhada e adicionou-se $25 \pm 1 \mathrm{~mL}$ de isopropanol e 15 $\pm 1 \mathrm{~mL}$ de acetona, utilizando os volumes para rinsar o béquer que continha a amostra. Acrescentou-se $125 \pm 1 \mathrm{~mL}$ de água deionizada pré-aquecida em torno de $80^{\circ} \mathrm{C}$ para melhor extração.

A mistura foi submetida à agitação constante em um agitador magnético utilizando barra magnética oval $(30 \mathrm{x} 10 \mathrm{~mm})$ por 30 min. Tomou-se o cuidado de não agitar vigorosamente a amostra para prevenir a formação de emulsões. Após o término da agitação, transferiu-se a mistura para um funil de separação simples e, após a separação das duas fases, drenou-se a fase inferior (fase aquosa), utilizando-se um papel de filtro para reter algum óleo.

\section{Determinação do IST na fase aquosa por potenciometria}

O procedimento para a determinação do IST por potenciometria no extrato aquoso, obtido pela extração por agitação mecânica sem aquecimento, é idêntico ao utilizado na determinação de sal no extrato aquoso obtido pela extração em frascos extratores a quente, descrito anteriormente.

\section{RESULTADOS E DISCUSSÃO}

O controle da qualidade dos óleos dessalgados é uma tarefa importante dos laboratórios de análise de petróleo, os quais geralmente efetuam análises sucessivas de amostras para avaliação da salinidade das correntes. Contudo, mesmo em laboratório a caracterização de petróleos é complexa. Apesar dos métodos utilizados obedecerem às normas técnicas padronizadas, o que poderia assegurar a adequação dos procedimentos, a prática tem mostrado que nem sempre as normas são apropriadas para determinados tipos de petróleo. Diante deste cenário, percebe-se a importância prática de se desenvolver metodologias alternativas e de se aperfeiçoarem as metodologias já existentes, a fim de se fornecer estimativas confiáveis sobre o teor de sais em petróleos. Em trabalhos recentes, Fortuny e colaboradores ${ }^{10,11}$ desenvolveram novo procedimento de extração e análise de sal em óleo pesado através de extração com água e titulação volumétrica (Möhr).

No caso particular dos estudos da caracterização do teor de sais efetuados neste trabalho, a norma técnica existente ${ }^{8}$ foi avaliada para assim se sugerirem algumas modificações de modo a aumentar a eficiência da extração, diminuir as projeções e minimizar os prejuízos ocorridos durante as extrações e para que normas alternativas possam ser propostas com intuito de reduzir certas deficiências identificadas com o decorrer da prática laboratorial do método padrão. ${ }^{8}$

\section{Otimização do sistema de extração a quente utilizando frascos extratores}

A utilização do sistema extrator conforme método padrão ${ }^{8}$ empregando-se frascos de $500 \mathrm{~mL}$ tem mostrado grandes dificuldades e prejuízos na execução das extrações, uma vez que causa projeções ou inundações do condensador, resultando em perda da análise. Outro ponto a se considerar é a segurança do processo, devido às violentas projeções que podem provocar acidentes com riscos para o analista.

As análises dos IST's, expressos em teores de cloretos por serem os mais abundantes, foram realizadas em amostras de petróleo utilizadas em programas interlaboratoriais (analisadas por diversos laboratórios) enviada pelo CENPES - PETROBRAS e amostra de referência de padrão secundário ou interno adotada pelo Labpetro para controle de qualidade do laboratório. Estas análises foram realizadas conforme ASTM D 6470, ${ }^{8}$ efetuando-se extrações de sais de cada padrão, tanto no tempo denominado de "Tempo ASTM" quanto no tempo denominado de "Tempo otimizado", descritos na parte experimental. Este "Tempo otimizado" foi avaliado pela necessidade de um tempo excedente para garantir a eficiência da extração de óleos com teores de sais mais elevados.

\section{Otimização do método utilizando amostra interlaboratorial}

As avaliações utilizando a amostra de referência interlaboratorial foram realizadas com frasco de extração modificado de capacidade de 2 L (Figura 1). Neste frasco, a superfície do líquido está a uma distância maior do condensador de refluxo, diminuindo a possibilidade de perdas por projeções. Os resultados obtidos para a amostra interlaboratorial estão listados na Tabela 1 e foram utilizados para a realização da análise estatística desta amostra de referência.

Tabela 1. Resultados do IST da amostra interlaboratorial no "Tempo ASTM" e no "Tempo otimizado"

\begin{tabular}{lcc}
\hline & $\begin{array}{c}\text { IST (ppm) no "Tempo } \\
\text { ASTM" }\end{array}$ & $\begin{array}{c}\text { IST (ppm) no "Tempo } \\
\text { otimizado" }\end{array}$ \\
\hline Extração 1 & 4,46487 & 6,65489 \\
Extração 2 & 5,55974 & 5,54693 \\
Extração 3 & 3,85985 & 4,19588 \\
Extração 4 & 4,11816 & 3,83162 \\
Extração 5 & 4,60818 & 6,24676 \\
\hline
\end{tabular}

Compararam-se os resultados obtidos pelo método otimizado no Labpetro com o valor da amostra interlaboratorial, que constam na Tabela 2. Este resultado da amostra de referência internacional é obtido através de um relatório final dos resultados das análises interlaboratoriais realizadas até novembro de 2007, em que oito 
resultados foram validados estatisticamente, obtendo-se a média e o desvio padrão desta amostra de óleo cru.

Tabela 2. Médias de IST, desvio padrão e z-escore da amostra interlaboratorial

\begin{tabular}{lcccc}
\hline Tempo & $\bar{x}$ LABPETRO & $\mu$ ASTM & $\sigma$ ASTM & z-escore \\
\hline ASTM & 4,522160 & 7 & 9 & $-0,27531556$ \\
Otimizado & 5,295216 & 7 & 9 & $-0,18942044$ \\
\hline
\end{tabular}

O dado do z-score mostrado na Tabela 2 é encontrado dividindo-se o resultado da subtração da média encontrada no Labpetro $(\bar{x})$ e da média da amostra interlaboratorial $(\mu)$ pelo desvio padrão da amostra de referência $\operatorname{ASTM}(\sigma)$, de acordo com a Equação 1:

$$
z=\frac{\bar{x}-\mu}{\sigma}
$$

onde: $z$ é o valor de z-escore; $\bar{x}$ é a média de IST obtido no Labpetro; $\mu$ é a média de IST da amostra interlaboratorial; $\sigma$ é o desvio padrão amostra interlaboratorial.

Para as análises feitas, o valor encontrado para o Z-score encontrase dentro de uma faixa aceitável, que é entre -2 a +2 . O desvio padrão para a amostra interlaboratorial é muito alto, resultando num valor de z-escore (para os resultados do Labpetro) pequeno, pois o intervalo de confiança obtido para a amostra interlaboratorial é grande. Com isso, os dois resultados obtidos ("Tempo ASTM" e "Tempo otimizado") estão dentro do limite de reprodutibilidade exigida, pois os valores de z-escore encontrados para os resultados Labpetro são bem menores e, portanto, mais precisos. Logo, o frasco de $500 \mathrm{~mL}$ pode ser substituído pelo de $2 \mathrm{~L}$.

Para as próximas comparações, será utilizado o intervalo de confiança obtido pelas análises feitas pelo Labpetro, pois este intervalo é menor, resultando em análises mais rigorosas.

As modificações no tempo de extração foram avaliadas como um tempo excedente para verificar se haveria a necessidade de um período superior para a extração dos óleos. Na comparação dos tempos de extração, primeiro se avaliou a diferença nas variâncias das amostras, por meio da distribuição F de Snedecor, calculada de acordo com a Equação 2:

$$
F_{\text {calc }}=\frac{S_{1}^{2}}{S_{2}^{2}}, \text { se } S_{1}^{2}>S_{2}^{2}
$$

onde: $F_{\text {calc }}=$ valor de $F$ calculado; $S^{2}=$ variância do grupo, onde (1) "Tempo ASTM" e (2) "Tempo otimizado".

Na Tabela 3 estão os resultados obtidos pelo "Teste F" a respeito dos dois grupos de análises, "Tempo ASTM" e "Tempo otimizado". O Teste unicaudal é utilizado para verificar se um método é melhor que o tradicional.

Tabela 3. Reultados do "Teste F" para os resultados do IST no "Tempo ASTM" e no "Tempo otimizado"

\begin{tabular}{lcc}
\hline & "Tempo ASTM" & "Tempo otimizado" \\
\hline Média IST (ppm) & 4,52216 & 5,295216 \\
Variância & 0,42228109 & 1,54204055 \\
Quantidade de dados & 5 & 5 \\
Graus de liberdade & 4 & 4 \\
F calculado & 3,651692134 & \\
F crítico unicaudal (tabelado) & 6,388232909 & \\
\hline
\end{tabular}

Como o valor de $F_{\text {calc }}<F_{\text {Tab }}$ não se rejeita, ao nível de $95 \%$ de confiança, a hipótese de homogeneidade das variâncias. Logo, presumindo variâncias equivalentes, ou seja, não havendo diferença nas variâncias fez-se o "Teste t", onde $t_{\text {calc }}$ é obtido através da Equação 3:

$$
t_{\text {calc }}=\frac{\left|\bar{x}_{1}-\bar{x}_{2}\right|}{S_{P} \cdot \sqrt{\frac{1}{n_{1}}+\frac{1}{n_{2}}}}
$$

onde: $t_{\text {calc }}=\mathrm{o}$ valor de $t$ calculado; $n=$ quantidade de dados do grupo: (1) "Tempo ASTM" e (2) "Tempo otimizado"; $\bar{x}=$ média dos dados do grupo, onde (1) "Tempo ASTM" e (2) "Tempo otimizado"; $S_{P}=$ desvio padrão ponderado, dado pela Equação 4:

$$
S_{P}=\sqrt{\frac{\left(n_{1}-1\right) \cdot S_{1}^{2}+\left(n_{2}-1\right) \cdot S_{2}^{2}}{n_{1}+n_{2}-2}}
$$

E o número de graus de liberdade é dado pela Equação 5:

$v=n_{1}+n_{2}-2$

Na Tabela 4 constam os resultados do "Teste t" dos dois grupos de análises, "Tempo ASTM" e "Tempo otimizado", presumindo variâncias equivalentes.

Tabela 4. Resultados do "Teste t" para os resultados do IST no "Tempo ASTM" e no "Tempo otimizado"

\begin{tabular}{lcc}
\hline & "Tempo ASTM" & "Tempo otimizado" \\
\hline Média IST (ppm) & 4,52216 & 5,295216 \\
Variância & 0,42228109 & 1,54204055 \\
Quantidade de dados & 5 & 5 \\
Graus de liberdade & 8 & 8 \\
Variância agrupada & 0,982160822 & \\
Hipótese da diferença de média & 0 & \\
t calculado & 1,233359424 & \\
t crítico bicaudal (tabelado) & 2,306004133 & \\
\hline
\end{tabular}

Como o valor de $t_{\text {calc }}<t_{\text {Tab }}$ não se rejeita, ao nível de $95 \%$ de confiança, a hipótese de igualdade entre as médias, ou seja, não há diferença estatisticamente significativa entre as médias. O teste bicaudal é utilizado para verificar se há diferença estatisticamente significativa entre os métodos e se um dos métodos pode ser melhor ou pior.

\section{Otimização do método utilizando amostra de referência interna}

No caso da amostra de referência secundária interna, este foi analisado utilizando-se frasco extrator de $500 \mathrm{~mL}$, conforme ASTM D $6470^{8}$ e também em frasco de $2 \mathrm{~L}$ para se obter um valor de referência desta amostra. Os resultados obtidos estão na Tabela 5 e estes foram utilizados para a realização da análise estatística desta amostra de referência. Os resultados de salinidade para esta amostra foram bem superiores comparados com a amostra de referência interlaboratorial, pois este é classificado como um petróleo pesado ( ${ }^{\circ} \mathrm{API}$ de 16,8 ) e normalmente apresenta maior teor de sais em sua constituição.

Para avaliar a homogeneidade entre as variâncias dos resultados obtidos pelo método de extração em frascos de $500 \mathrm{~mL}$ e 2 L no "Tempo ASTM" realizou-se o "Teste F" e os dados constam na Tabela 6.

Avaliou-se também a homogeneidade entre as variâncias dos resultados obtidos pelo método de extração em frascos de $500 \mathrm{~mL}$ e 2 L no "Tempo ASTM"; efetuou-se o "Teste F" e os dados obtidos constam na Tabela 7.

Nos dois casos o valor de $F_{\text {calc }}$ é menor que o valor de $F_{T a b}$ e com isso não se rejeita a hipótese de homogeneidade entre as variâncias. A partir destes resultados realizou-se o "Teste $t$ " para os dois casos, assumindo-se variâncias homogêneas e os dados obtidos constam nas Tabelas 8 e 9. 
Tabela 5. Resultados de salinidade obtidos a partir do Padrão Secundário

\begin{tabular}{lcc}
\hline $\begin{array}{l}\text { IST (ppm) extraído } \\
\text { em frasco de 500 mL } \\
\text { no "Tempo ASTM" }\end{array}$ & $\begin{array}{c}\text { IST (ppm) extraído } \\
\text { em frasco de 2 L no } \\
\text { "Tempo ASTM" }\end{array}$ & $\begin{array}{l}\text { IST (ppm) extraído } \\
\text { em frasco de 2 L no } \\
\text { "Tempo otimizado" }\end{array}$ \\
\hline 41,15006 & 44,26101 & 48,38886 \\
40,43140 & 43,24159 & 49,26709 \\
41,56485 & 43,67467 & 51,11496 \\
- & 43,65301 & 49,85136 \\
- & - & 52,78732 \\
\hline
\end{tabular}

Tabela 6. Resultados do "Teste F" para os resultados do IST na extração com frasco de 500 mL no "Tempo ASTM" e na extração com frasco de 2 L no "Tempo ASTM"

\begin{tabular}{lcc}
\hline & $\begin{array}{c}\text { IST (ppm) extraído } \\
\text { em frasco de 500 mL } \\
\text { no “Tempo ASTM" }\end{array}$ & $\begin{array}{c}\text { IST (ppm) extraído } \\
\text { em frasco de 2 L } \\
\text { no “Tempo ASTM" }\end{array}$ \\
\hline Média & 41,04877 & 43,70757 \\
Variância & 0,32887197 & 0,1758308 \\
Quantidade de dados & 3 & 4 \\
Graus de liberdade & 2 & 3 \\
F calculado & 1,87038889 & \\
F crítico unicaudal (tabelado) & 9,5520945 & \\
\hline
\end{tabular}

Tabela 7. Resultados do "Teste F" para os resultados do IST na extração com frasco de 500 mL no "Tempo ASTM" e na extração com frasco de 2 L em "Tempo otimizado"

\begin{tabular}{lcc}
\hline & $\begin{array}{c}\text { IST (ppm) extraído em } \\
\text { frasco de 500 mL no } \\
\text { "Tempo ASTM" }\end{array}$ & $\begin{array}{c}\text { em fraspo de 2 L no } \\
\text { "Tempo otimizado" }\end{array}$ \\
\hline Média & 41,04877 & 50,281918 \\
Variância & 0,32887197 & 2,9424807 \\
Quantidade de dados & 3 & 5 \\
Graus de liberdade & 2 & 4 \\
F calculado & 8,94719203 & \\
F crítico unicaudal (tabelado) & 19,2467943 & \\
\hline
\end{tabular}

Avaliando os resultados do "Teste t" tem-se que, nos dois casos, os valores de $t_{\text {calc }}>t_{\text {tab }}$ e, portanto, rejeita-se a hipótese de igualdade entre as médias em ambos as análises, ou seja, há diferença estatisticamente significativa entre as médias.

Nos dois "Testes t" realizados, os resultados de IST utilizando o frasco de $2 \mathrm{~L}$ foram superiores ao método ASTM utilizando o frasco de $500 \mathrm{~mL}$, conforme o gráfico IST versus frascos de extração (Figura 2). Como os resultados de IST foram superiores ao se empregar frasco de 2 L e também com a utilização do tempo otimizado, não há perda na análise de salinidade se ambas as modificações forem efetuadas.

O fato dos teores de sais obtidos (em IST) nas extrações realizadas em frasco de $2 \mathrm{~L}$ terem sido maiores comparados às extrações em frasco de $500 \mathrm{~mL}$ (Figura 2) pode ser explicado pelo maior tempo (tempo otimizado) de extração e a maior superfície de contato entre os líquidos (ver Figura 1).

\section{Desenvolvimento de um sistema de extração utilizando frascos erlenmeyer sem aquecimento constante}

Diante dos altos riscos operacionais que o sistema de extração a quente proporciona, foi desenvolvido um estudo de um sistema de extração de sais utilizando frasco erlenmeyer com agitadores magnéticos e sem ebulição para o monitoramento do teor de sais, a fim de disponibilizar uma rota opcional de extração de sais em petróleo. Foram escolhidas amostras do tipo blend por serem óleo do tipo leve ( ${ }^{\circ} \mathrm{API}$ de 32,0 ), o que
Tabela 8. Resultados do "Teste t" para os resultados do IST na extração com frasco de 500 mL no "Tempo ASTM" e na extração com frasco de 2 L no "Tempo ASTM"

\begin{tabular}{lcc}
\hline & $\begin{array}{c}\text { IST (ppm) extraído } \\
\text { em frasco de 500 mL } \\
\text { no "Tempo ASTM" }\end{array}$ & $\begin{array}{c}\text { IST (ppm) extraído } \\
\text { em frasco de 2 L } \\
\text { no "Tempo ASTM" }\end{array}$ \\
\hline Média & 41,04877 & 43,70757 \\
Variância & 0,328871974 & 0,175830799 \\
Quantidade de dados & 3 & 4 \\
Variância agrupada & 0,237047269 & \\
Hipótese da diferença de média & 0 & \\
Graus de liberdade & 5 & \\
t calculado & 7,150061791 & \\
t crítico bicaudal (tabelado) & 2,570581835 & \\
\hline
\end{tabular}

Tabela 9. Resultados do "Teste t" para os resultados do IST na extração com frasco de $500 \mathrm{~mL}$ no "Tempo ASTM" e na extração com frasco de 2 L no "Tempo Otimizado"

\begin{tabular}{lcc}
\hline & $\begin{array}{c}\text { IST (ppm) extraído } \\
\text { em frasco de 500 mL } \\
\text { no “Tempo ASTM" }\end{array}$ & $\begin{array}{c}\text { IST (ppm) extraído } \\
\text { em frasco de 2 L no } \\
\text { "Tempo otimizado" }\end{array}$ \\
\hline Média & 41,04877 & 50,281918 \\
Variância & 0,328871974 & 2,942480702 \\
Quantidade de dados & 3 & 5 \\
Variância agrupada & 2,071277793 & \\
Hipótese da diferença de média & 0 & \\
Graus de liberdade & 6 & \\
t calculado & 8,78478746 & \\
t crítico bicaudal (tabelado) & 2,446911846 & \\
\hline
\end{tabular}

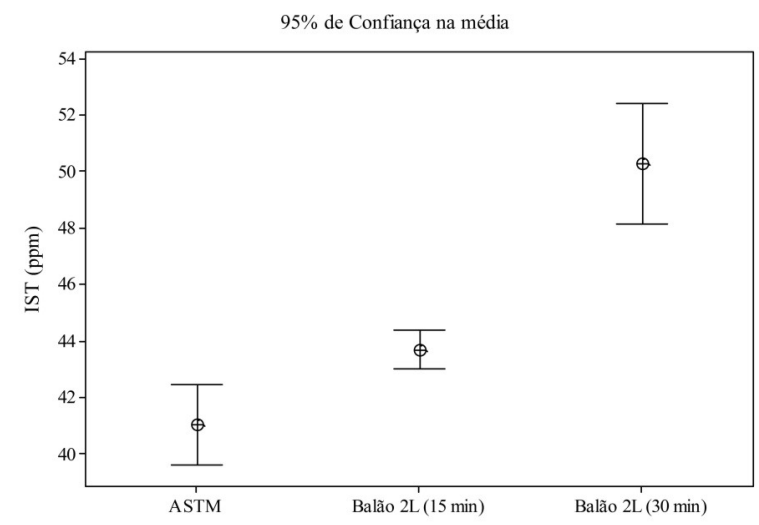

Figura 2. Intervalos de IST encontrados nas diferentes metodologias

facilita a homogeneização das amostras com os solventes. Além disso, este tipo de petróleo acarreta maiores problemas quando submetido ao sistema de extração em frascos extratores em ebulição devido à alta liberação de frações leves, ocasionando projeções de grandes proporções, fato esse que levou ao desenvolvimento deste trabalho. Para este estudo foram efetuadas, simultaneamente, extrações em frascos extratores em triplicata a quente e em frascos erlenmeyer sem aquecimento para fins comparativos. As médias dos resultados obtidos, listadas na Tabela 10, foram utilizadas para a realização da análise estatística destas amostras.

Realizou-se o "Teste t" com as médias dos IST's encontrados pelo método de extração pelos frascos extratores a quente e frascos erlenmeyer sem aquecimento e os dados obtidos estão contidos na Tabela 11. Mais uma vez foi utilizado o Teste bicaudal para verificar se há diferença estatisticamente significativa entre os métodos. 
Tabela 10. Resultados das análises de IST das extrações a quente e sem aquecimento

\begin{tabular}{lcc}
\hline Amostra & $\begin{array}{c}\text { IST }(\mathrm{ppm}) \\
\text { "Extração a quente" }\end{array}$ & $\begin{array}{c}\text { IST }(\mathrm{ppm}) \\
\text { "Extração sem aquecimento" }\end{array}$ \\
\hline A & 196,360 & 161,863 \\
B & 388,148 & 344,116 \\
C & 521,375 & 557,977 \\
D & 334,113 & 279,659 \\
E & 121,066 & 108,941 \\
F & 331,683 & 321,110 \\
G & 105,610 & 89,786 \\
H & 184,850 & 151,723 \\
\hline
\end{tabular}

Tabela 11. Resultados do "Teste t" para os resultados de IST das extrações a quente e sem aquecimento

\begin{tabular}{lcc}
\hline & $\begin{array}{c}\text { IST (ppm) "Extração } \\
\text { a quente" }\end{array}$ & $\begin{array}{c}\text { IST (ppm) "Extração } \\
\text { sem aquecimento" }\end{array}$ \\
\hline Média & 272,9006488 & 251,8972 \\
Variância & 20982,11253 & 24658,27 \\
Quantidade de dados & 8 & 8 \\
Correlação de Pearson & 0,985953261 & \\
Hipótese da diferença de média & 0 & \\
Graus de liberdade & 7 & \\
t calculado & 2,117214103 \\
t crítico bicaudal (tabelado) & 2,364624251 & \\
\hline
\end{tabular}

Como o valor do $t_{c a l c}>t_{t a b}$, não se rejeita a hipótese nula, ou seja, não há diferença estatisticamente significativa, ao nível de $95 \%$ confiança, entre as médias.

Para este petróleo, utilizando a média das diferenças entre os resultados compararam-se os resultados dos IST's obtidos pelas extrações em frascos extratores a quente e em frascos erlenmeyer sem aquecimento. O resultado está apresentado na Figura 3, onde $\bar{x}$ representa a média das diferenças dos valores das extrações e Ho é o valor ideal para essa média.

Observa-se que a maioria dos resultados está dentro do intervalo da média das diferenças $(\bar{x})$ com intervalo de confiança de $95 \%$. Outro fato importante é que este intervalo da média das diferenças também está englobando Ho, mostrando que não há diferença significativa entre eles.

Com a realização do "Teste t" em conjunto com a avaliação da média das diferenças encontradas pode-se concluir que o método de extração de sais em frascos erlenmeyer sem aquecimento pode ser utilizado como uma rota alternativa para análises de sais em óleos leves.

\section{CONCLUSÕES}

Este trabalho possibilitou demonstrar que o frasco de $2 \mathrm{~L}$ pode ser implementado ao sistema de extração a quente visando otimizar o método ASTM D 6470, visto que o resultado obtido com a amostra de referência interlaboratorial está dentro do limite de reprodutibilidade exigida. Mostrou-se também que para a amostra de referência secundária, os resultados de IST foram superiores para o frasco de $2 \mathrm{~L}$, portanto não há prejuízo na análise de salinidade se houver a substituição pelo frasco de $2 \mathrm{~L}$.

Verificou-se ainda que um aumento no tempo de extração em óleos com baixo teor de sais, em torno de 5 ppm (amostra interlaboratorial), não acarretou diferença estatisticamente significativa entre as médias. No entanto, quando estas mesmas modificações no tempo de extração foram submetidas ao petróleo (Referência Secundária Interna) com teor de sais mais elevado, em torno de $40 \mathrm{ppm}$, observou-se diferença estatisticamente significativa entre essas médias, proporcionando uma maior extração do sal. Pode-se concluir, então, que petróleos com teores de sais mais

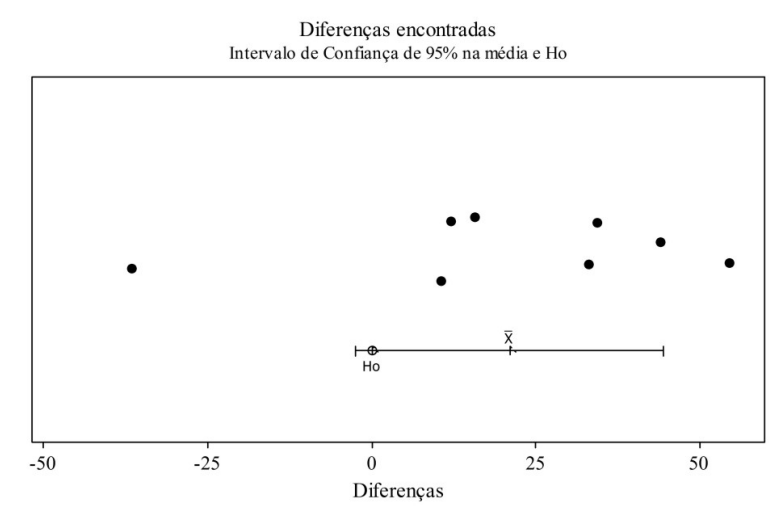

Figura 3. Resultado obtido para as diferenças entre extrações a quente e sem aquecimento

elevados requerem um tempo de extração excedente ao estabelecido pela norma ASTM para remover totalmente os sais do petróleo.

No caso do desenvolvimento de um sistema de extração de sais de petróleos em frascos erlenmeyer por agitação mecânica e sem aquecimento, os resultados obtidos foram submetidos às análises estatísticas de "Teste t” com a avaliação da média das diferenças. Os resultados mostraram que este método pode ser utilizado como uma rota alternativa para análises de sais em óleos leves e apontam para a viabilidade da aplicação desta técnica na extração de sais em petróleos leves motivando, então, a inserção da técnica e a perspectiva futura de se avaliar a eficiência deste método para petróleos médios e pesados.

Por meio deste trabalho pode-se perceber a extrema importância de se desenvolver novas metodologias e de se aprimorar as metodologias já empregadas para extração de sais de modo que se tenham técnicas mais rápidas, seguras e eficientes. Como as refinarias trabalham com especificações muito rigorosas e assim, para garantia da qualidade dos petróleos, torna-se necessário adaptar os métodos tradicionais de laboratório aos diferentes tipos de óleos encontrados.

\section{AGRADECIMENTOS}

À FINEP, ANP, CST ARCELORMITTAL e à PETROBRAS.

\section{REFERÊNCIAS}

1. Ramalho, J. B. V. S.; Bol. Téc. PETROBRAS 2002, 45, 1.

2. Mariano, J. B.; Impactos Ambientais do Refino do Petróleo, Interciência: Rio de Janeiro, 2005.

3. Thomas, J. E.; Fundamentos de Engenharia de Petróleo, Interciência: Rio de Janeiro, 2004.

4. Abdul-Wahab, S.; Elkamel, A.; Madhuranthakam, C. R.; Al-Otaibi, M. B.; Chemical Enginheering and Processing 2006, 45, 568

5. Oliveira, R. C. G.; Bol. Téc. PETROBRAS 2000, 43, 111.

6. Al-Otaibi, M. B.; Elkamel, A.; Nassehi, V.; bdul-Wahab, S. A.; Energy Fuels 2005, 19, 2526.

7. American Society for Testing Materials; Standard D 512 Standard Test Methods for Chloride Ion In Water, 2004.

8. American Society for Testing Materials; Standard D 6470 Standard test method for salt in crude oils (potentiometric method), 2004.

9. American Society for Testing Materials; Standard D 3230 Standard Test Method for Salts in Crude Oil (Electrometric Method), 2008.

10. Fortuny, M.; Silva, E. B.; Filho, A. C.; Melo, R. L. F. V.; Nele, M.; Coutinho, R. C. C.; Santos, A. F.; Fuel 2008, 87, 1241.

11. Fortuny, M.; Ramos, A. L. D.; Dariva, C.; Egues, S. M. D.; Santos, A. F.; Nele, M.; Coutinho, R. C. C.; Quim. Nova 2008, 31, 1553. 